\section{A simple technique to aid intubation of the duodenoscope in the afferent limb of Billroth II gastrectomies for endoscopic retrograde cholangiopancreatography}

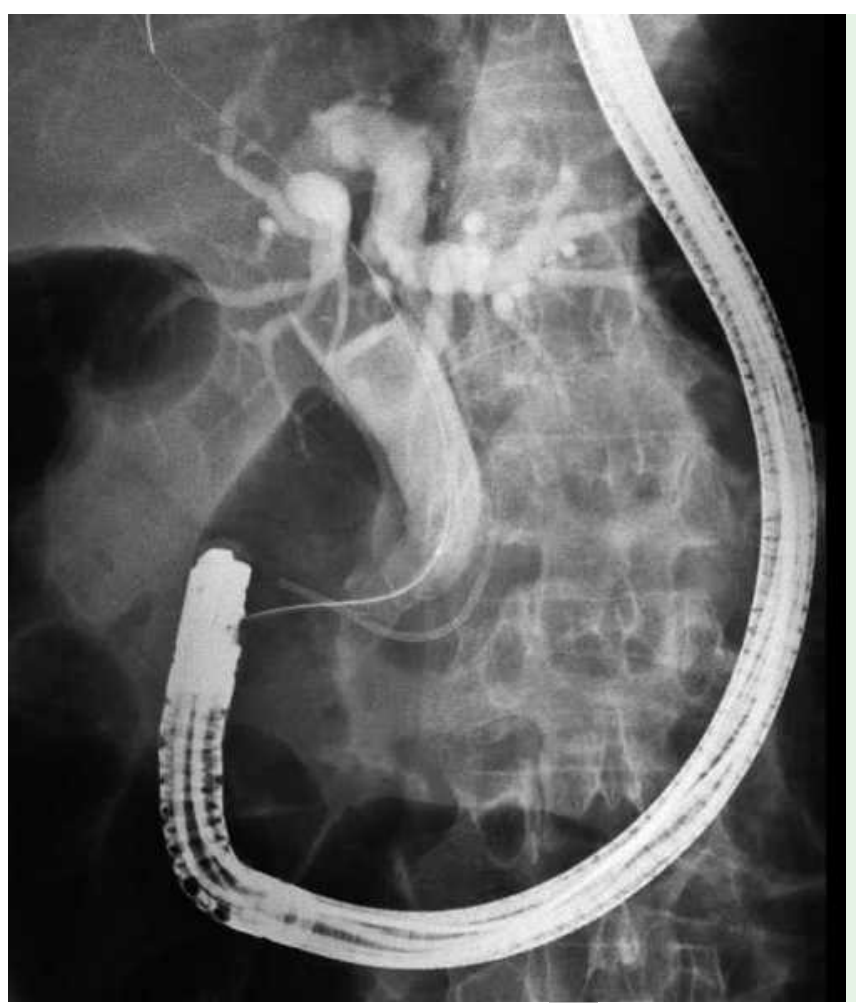

Billroth II gastrectomy poses a challenge for the endoscopist performing endoscopic retrograde cholangiopancreatography (ERCP). The papilla appears in a reversed position in the endoscopic view, making cannulation more difficult ( $\odot$ Fig. 1, 2). The initial problem usually encountered is that of finding the afferent loop and advancement of the duodenoscope to the papillary area. Negotiating the stoma and the afferent limb is a recognized cause of bowel perforation $[1,2]$. The use of forward-viewing endoscopes can be sometimes helpful for ERCP in these patients [3], and perforation has rarely been reported when these instruments are used. Nevertheless, some of the duodenoscope's properties (e.g. the elevator) are sometimes necessary for biliary or pancreatic interventions in patients with Billroth II gastrectomies. A simple technique for reaching the papillary area in patients with this type of gastrectomy is described here.

With the patient in the prone position for ERCP, a forward-viewing, routine gastroscope is passed into the stomach and the afferent limb is intubated to its end. A Savary guide wire is passed through the working channel of the endoscope. The gastroscope is then removed, leaving the guide wire in place ( $\bullet$ Fig. 3 ). The duodenoscope is then passed alongside the Savary guide wire. In the stomach, the guide wire marks the path to the afferent limb.

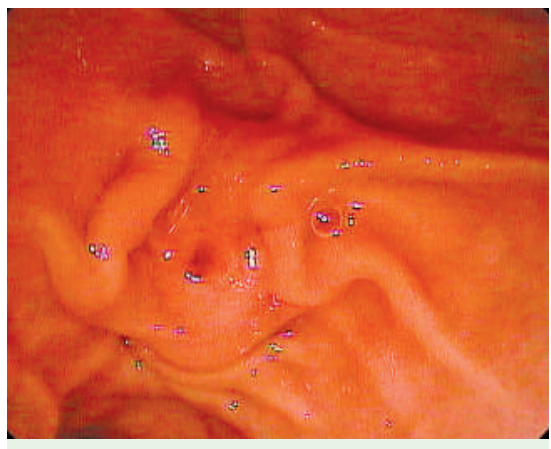

Fig. 2 In patients with a Billroth II gastrectomy, the ampulla is seen in a reversed position in the duodenoscopic view.

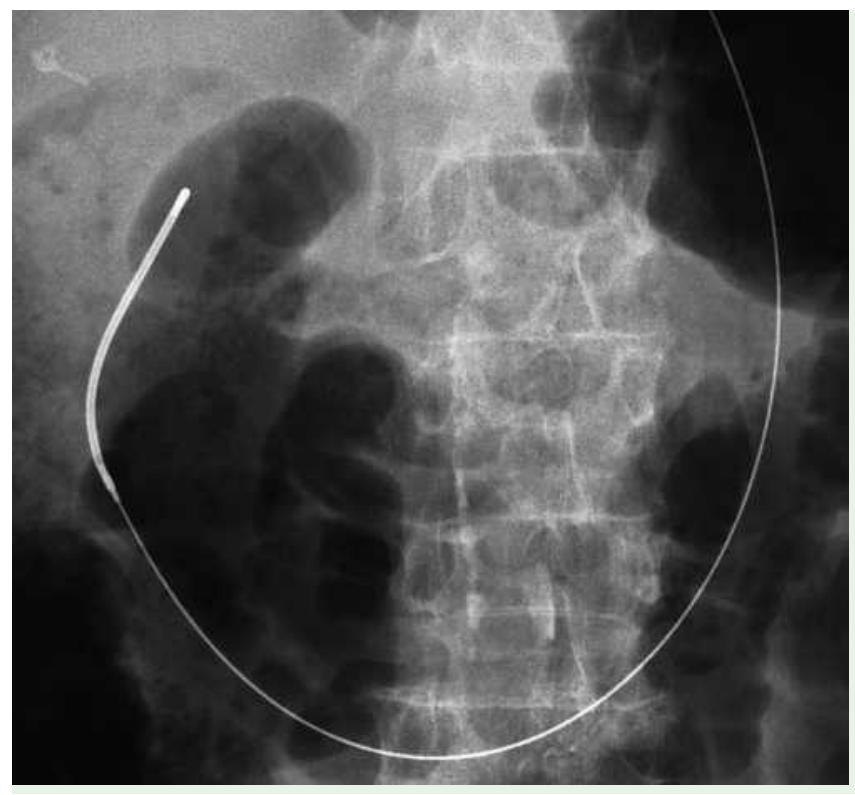

Fig. 3 This radiographic view shows a Savary guide wire that has been left in place in the afferent limb of a Billroth II gastrectomy. This guide wire marks the route to the papillary area and facilitates the advancement of a duodenoscope for endoscopic retrograde cholangiopancreatography. 
With the aid of fluoroscopy and the endoscopic view, the dudenoscope is then pushed forward, following the guide wire. In order to avoid perforation, the endoscopist should be careful not to straighten the limb forcibly.

The scope is advanced partly by gently pushing and withdrawing, by torquing the shaft with the hand, using the wheels as little as possible. Advancing the scope side-by-side with the guide wire has proved to be more useful than backloading it in the duodenoscope channel and gliding the instrument over the guide wire. The endoscope can usually be placed in front of the papilla quite quickly using this method.

Endoscopy_UCTN_Code_TTT_1AR_2AB

\section{J. García-Cano}

Section of Digestive Diseases, Hospital

Virgen de la Luz, Cuenca, Spain

\section{References}

1 Faylona JMV, Qadir A, Chan ACW et al. Smallbowel perforations related to endoscopic retrograde cholangiopancreatography (ERCP) in patients with Billroth II gastrectomy. Endoscopy 1999; 31: 546 - 549

2 García-Cano Lizcano J, González Martín JA, Morillas Ariño J et al. Complications of endoscopic retrograde cholangiopancreatography: a study in a small ERCP unit. Rev Esp Enferm Dig 2004; 96: 163 - 173

3 García-Cano J. Insertion of a Zilver biliary stent by means of a routine gastroscope in a jaundiced patient with a Billroth II gastrectomy. J Clin Gastroenterol 2004; 38: $835-836$
Bibliography

DOI $10.1055 / \mathrm{s}-2007-966950$

Endoscopy 2008; 40: E21 -E22

(c) Georg Thieme Verlag KG Stuttgart · New York . ISSN 0013-726X

Corresponding author

\section{J. García-Cano, MD}

Section of Digestive Diseases

Hospital Virgen de la Luz

16002 Cuenca

Spain

Fax: +34-969-230407

j.garcia-cano@terra.es 